\title{
Immunochemical analysis and possible biological role of an Aeromonas hydrophila surface array protein in septicaemia
}

\author{
Robert P. KokKa, ${ }^{1,2}$ Neylan A. Vedros ${ }^{2}$ and J. Michael Janda ${ }^{1 *}$ \\ ${ }^{1}$ Microbial Diseases Laboratory, California Department of Health Services, Berkeley, CA 94704-1011, USA \\ ${ }^{2}$ Biomedical and Environmental Health Sciences, School of Public Health, University of California, Berkeley, \\ CA 94720, USA
}

(Received 1 October 1991; revised 4 February 1992; accepted 13 February 1992)

\begin{abstract}
The biochemical, immunological, and biological properties of an $\mathrm{S}$ layer purified from an Aeromonas hydrophila strain (AH-342) involved in a case of bacteraemia were investigated. The $S$ layer selectively removed from the cell surface was composed of a single acidic (pI 4.65) protein subunit (surface array protein, SAP) with a molecular mass of approximately $52 \mathrm{kDa}$. Amino acid analysis of this $52 \mathrm{kDa}$ protein indicated a molecule composed of 498 amino acids with $46 \%$ hydrophobic residues. No cysteine residues were detected. The first 35 residues of the Nterminus were sequenced by Edman degradation; only 4-24\% homology was noted between this sequence and those previously published for SAPs of Aeromonas salmonicida (A450) and a strain of $A$. hydrophila (TF7) originally isolated from a moribund fish. Polyclonal antibodies raised against AH-342 SAP were genospecific, reacting only against $S$ layers produced by $A$. hydrophila strains and not those from Aeromonas veronii. Acute serum from the bacteraemic patient from whom AH-342 was isolated reacted strongly with the SAP of AH-342 in immunoblot studies. Purified SAP, when intraperitoneally co-inoculated with SAP- strains of $A$. hydrophila into SwissWebster mice, could reduce the $50 \%$ lethal dose by approximately $30-70$ fold. The results suggest that the SAP of $A$. hydrophila strains may play an important role in systemic dissemination after invasion through the gastrointestinal mucosa.
\end{abstract}

\section{Introduction}

We have recently identified a major subgroup of Aeromonas hydrophila and Aeromonas veronii strains that are preferentially involved in a wide variety of human extraintestinal illnesses, such as septicaemia, peritonitis, and fulminant wound infections (Kokka et al., 1991 a). Less frequently, this subgroup has also been implicated in gastrointestinal infections clinically resembling Crohn's disease, enterocolitis, and typhoid fever (Kokka $\&$ Janda, 1990). Two useful phenotypic markers which aid in the recognition of this subgroup are the ability to autoagglutinate in broth and the presence of a common somatic antigen of serogroup O:11 (Kokka \& Janda, 1990). Seroepidemiologic surveys using these two markers indicate the $0: 11$ group to be one of the two (of over 80 known) most common serogroups associated with human disease, accounting for $20-30 \%$ of all $A$.

\footnotetext{
* Author for correspondence. Tel. (510) 5402242 ; fax (510) 5402374.

The amino acid sequence data reported in this paper have been submitted to PIR and have been assigned the accession number A33184.
}

hydrophila and A. veronii (formerly $A$. sobria) infections. Subsequent investigations have also noted that the frequency of isolation of Aeromonas O:11 from clinical, as opposed to environmental sources, is at least four-fold higher, suggesting that this serogroup is more likley to cause significant human disease (Paula et al., 1988).

Additional features shared by all 0:11 $\mathrm{A}$. hydrophila and $A$. veronii strains are the possession of an $S$ layer, and enhanced pathogenicity in mice as determined by $50 \%$ lethal dose assays (Paula et al., 1988; Kokka et al., $1991 a$ ). The $\mathrm{S}$ layer, which is located on the outermost surface of the bacterium, is composed of a single acidic protein molecule (termed the surface array protein, SAP) with a molecular mass of 52-55 kDa (Kokka et al., 1990). Possession of an $S$ layer appears to be unambiguously linked to this single serogroup and to a characteristic molecular architecture of LPS $O$-polysaccharide sidechains of this somatic group. Pathogenicity studies conducted on a representative number of $O: 11$ strains indicate this subgroup to be more virulent in outbred mice than counterpart non-O :11 strains, further supporting the clinical relevance of this subgroup. 
Table 1. Bacterial strains used in the present investigation

\begin{tabular}{|c|c|c|c|c|c|}
\hline Strain & Species & $\mathrm{HG} \dagger$ & Source & Comment $\ddagger$ & Reference $\S$ \\
\hline AH-342 & hydrophila & 1 & blood, human & $\mathrm{O}: 11, \mathrm{SAP}^{+}$ & This study \\
\hline NMRI-7 & hydrophila & 1 & wound, human & $\mathrm{O}: 34, \mathrm{SAP}^{-}$ & $a$ \\
\hline ATCC 15468 & caviae & 4 & guinea pig & $\mathrm{O}: 11$, (atypical), SAP- & $b$ \\
\hline NMRI-54 & hydrophila & 1 & river & $\mathbf{O}: 11, \mathbf{S A P}^{+}$ & $a$ \\
\hline AH-121 & hydrophila & 1 & wound, human & $\mathbf{O}: 11, \mathrm{SAP}^{+}$ & $a$ \\
\hline $1113-76$ & hydrophila & ND & faeces, human & $\mathrm{O}: 11, \mathrm{SAP}^{+}$ & $b$ \\
\hline A 179 & veronii & UG & animal & O:11 (atypical), SAP- & $b$ \\
\hline LL1 & hydrophila & 1 & trout & $\mathbf{O}: 11, \mathbf{S A P}^{+}$ & $a$ \\
\hline A310 & hydrophila & 2 & well water & O:11 (atypical), SAP- & $b$ \\
\hline AS- 180 & veronii* & 8 & blood, human & $\mathrm{O}: 11, \mathrm{SAP}^{+}$ & $a$ \\
\hline ATCC 9071 & veronii ${ }^{*}$ & 8 & frog & $\mathrm{O}: 11, \mathrm{SAP}^{+}$ & $a$ \\
\hline AS- 28 & veronii* ${ }^{*}$ & 8 & faeces, human & $0: 11 \mathrm{SAP}^{+}$ & $a$ \\
\hline
\end{tabular}

* These strains have been reclassified as $A$. veronii biotype sobria according to current taxonomic designations (see Kokka et al., 1991a).

$\dagger$ HG, hybridization group; UG, unknown group.

† SAP, surface array protein.

$\S$ References: $a$, Kokka et al. (1991a); $b$, Kokka et al. (1991b).

ND, not determined.

An attractive hypothesis is that the $\mathrm{S}$ layer is intimately involved in overt pathogenicity. However, published data from our laboratory to date do not support this concept, based upon the virulence of spontaneous mutants or atypical $\mathrm{O}: 11$ strains that are Slayer-negative yet still virulent for mice (Kokka et al., $1991 b$ ). Furthermore, enzymic or physiological manipulation of the relative amount of SAP produced by typical $0: 11$ strains does not apparently affect virulence, suggesting that the $\mathrm{S}$ layer is not directly involved in lethality in mice (Kokka et al., 1991 b). Nevertheless, the $S$ layer could be involved in earlier steps in pathogenicity, or in vivo regulation of $\mathrm{S}$ layer synthesis could affect the infectious process. Finally, the virulence potential of S-layer strains could in part be determined by potential antigenic or structural differences in Aeromonas SAPs, since we have previously shown two different species to produce structurally similar molecules. To address some of these issues, we have extensively characterized the SAP from a bacteraemic strain of $A$. hydrophila and shown that: (1) this is the immunodominant protein detected during the patient's septic episode; (2) SAPs from genetically related strains (e.g., A. hydrophila) show significant immunologic homology; and (3) the SAP appears to enhance the invasive potential of genetically identical strains by overcoming the normal phagocytic barriers.

\section{Methods}

Bacterial strains. Aeromonas strains used in the present study, with their relevant phenotypic and genotypic characteristics, are listed in
Table 1. All isolates were maintained on extract agar slants [18 g extract broth (Acumedia), $2 \mathrm{~g}$ beef extract, $15 \mathrm{~g}$ agar per litre].

Protein analysis and purification. Whole-cell (WC) protein extracts of Aeromonas were prepared as previously described (Kokka et al., 1990). $\mathrm{S}$-layer proteins were removed from cells by $0.2 \mathrm{M}$-glycine hydrochloride (pH 4.0) extraction. Briefly, the growth obtained from 60 heart-infusion agar plates was harvested in cold $20 \mathrm{mM}$-Tris (pH 8) and centrifuged at $7000 \mathrm{~g}$ for $30 \mathrm{~min}$ at $4{ }^{\circ} \mathrm{C}$. The resulting pellet was resuspended in $240 \mathrm{ml} 0.2 \mathrm{M}$-glycine $/ \mathrm{HCl}$. This suspension was gently mixed every $10 \mathrm{~min}$ for $30 \mathrm{~min}$. Glycine-treated cells were then removed by centrifugation $\left(7000 \mathrm{~g}, 30 \mathrm{~min}, 4^{\circ} \mathrm{C}\right)$, after which the surface array protein (SAP) material contained in the supernatant fraction was recovered by centrifugation at $30000 \mathrm{~g}$ for $30 \mathrm{~min}$. The resulting SAP pellets were resuspended in sterile distilled water, the protein concentration of the resuspended SAP was determined and the SAP material was subjected to isoelectric focusing (IEF). Some reconstituted pellets were dialysed against distilled water overnight and lyophilized for subsequent amino acid analysis and sequencing.

Gel electrophoresis and staining. WC $(1-30 \mu \mathrm{g})$ and glycine-extracted SAPs $(0.005-20 \mu \mathrm{g})$ were analysed by SDS-PAGE using $10 \%(\mathrm{w} / \mathrm{v})$ separating gels and $6 \%(\mathrm{w} / \mathrm{v})$ stacking gels; gels were stained with $0.1 \%$ Coomassie brilliant blue R-250 (Bio-Rad Laboratories).

Performic acid oxidation and amino acid composition and sequencing analysis. SAP was prepared for amino acid analysis and sequencing as described by Ho et al. (1990). Briefly, $1 \mathrm{ml}$ hydrogen peroxide was added to $9 \mathrm{ml} 88 \%(\mathrm{v} / \mathrm{v})$ formic acid, and the mixture was incubated for $1 \mathrm{~h}$ at room temperature before cooling on ice. A $200 \mu \mathrm{l}$ volume of this chilled preparation was added to a lyophilized sample $(30 \mu \mathrm{g})$ of $S$ layer protein. After $4 \mathrm{~h}$ at $4{ }^{\circ} \mathrm{C}$, the reaction was terminated by addition of $2 \mathrm{ml}$ water to the mixture; the sample was then dried prior to amino acid composition and sequencing analysis.

The amino acid composition was determined after hydrolysing the proteins in $6 \mathrm{M}-\mathrm{HCl}$ in vacuo at $110^{\circ} \mathrm{C}$ for 24,48 , and $72 \mathrm{~h}$, using Beckman 6300 and Durrum D-500 analysers. Methionine and cysteine residues were identified after performic acid oxidation of the proteins, but tryptophan residues are destroyed by this method and were not determined. Amino acid sequencing was performed by Edman 
degradation using a Beckman 890M and an Applied Biosystems 470A Sequencer in the presence of polybrene.

Polyclonal SAP antibodies. New Zealand white rabbits were injected intradermally at 10 different sites on the back of the rabbits with $0.1 \mathrm{ml}$ of an equivolume mixture containing SAP $(1.0 \mathrm{mg})$ from AH-342 and Freund's complete adjuvant (Gibco). After four weeks, rabbits were boosted subcutaneously with $1 \mathrm{mg}$ SAP in incomplete Freund's adjuvant at $0.2 \mathrm{ml}$ per site. After three weeks, a trial bleed was performed and the rabbit antisera were initially screened by slide agglutination assays with the homologous isolate to determine if there was a sufficient antibody response. The rabbits were killed by cardiac puncture and the resultant serum was stored at $-70^{\circ} \mathrm{C}$.

An initial titration of the anti-SAP antibody was performed by immunoblot assay using dilutions of WC suspensions of the homologous isolate and an S-layer-negative spontaneous mutant (AS-180-1) against increasing dilutions of the unabsorbed polyclonal antiserum. Dilutions of the antigen suspensions $(10 \mu \mathrm{l})$ were placed on nitrocellulose membranes, air-dried, covered with blocking buffer, and kept at room temperature for $1-2 \mathrm{~h}$. The sheets were washed in PBS and dried. Dilutions $(10 \mu \mathrm{l})$ of the unabsorbed anti-342 SAP antibody in blocking buffer were added to the nitrocellulose-antigen sheets and kept for $1 \mathrm{~h}$ at ambient temperature. The blots were subsequently washed with PBS, and dried. A second antibody (anti-IgG-Protein A-gold; E-Y Laboratories) was applied $(10 \mu \mathrm{l})$ and the blots were incubated for 10-30 min. The blots were then washed with PBS and read macroscopically.

The rabbit anti-342 SAP antisera were absorbed with whole-cell suspensions of homologous and heterologous strains of Aeromonas in order to increase the specificity of the antisera for the surface array protein. A total of six successive absorptions were performed using homologous and heterologous Aeromonas strains. The absorbed antiserum was centrifuged at $10000 \mathrm{~g}$ for $15 \mathrm{~min}$ and then filtered twice using a $0.45 \mu \mathrm{m}$ and $0.2 \mu \mathrm{m}$ Acrodisc filter (Gelman Sciences). Aliquots were stored at $-70^{\circ} \mathrm{C}$.

Immunoblotting. Electrotransfers on to nitrocellulose of SDS-PAGE gels containing $\mathrm{WC}$ and glycine-extracted $\mathrm{S}$ layers were performed using a Hoefer TE-50 power lid with the TE 42 transfer unit (Hoefer Scientific) and the Towbin buffer system (Kokka et al., 1991b). Immunoblotting was performed using the respective antisera (rabbit anti-SAP or human patient antisera) and Bio-Rad Immun-Blot Assay Kits as per the manufacturer's directions.

Decreasing amounts of glycine-extracted AH-342 SAP (5.0$0.005 \mu \mathrm{g}$ ) were run on SDS-PAGE gels, electrotransferred to nitrocellulose membranes and immunostained with varying dilutions of the polyclonal rabbit anti-342 SAP antibody. A 1:1000 antibody dilution was considered the optimal use dilution for subsequent immunoblotting experiments. Titrations of patient antisera were performed in a similar manner.

To assess the specificity of the polyclonal anti-SAP antibody, WC protein extracts $(0.5-1.0 \mu \mathrm{g})$ of the homologous (AH-342) and heterologous (five $0: 11, \mathrm{SAP}^{+}, A$. hydrophila, two $0: 11, \mathrm{SAP}^{-} A$. hydrophila, and three $\mathrm{O}: 11, \mathrm{SAP}^{+} A$. veronii) strains were electrophoresed on $10 \%$ SDS-PAGE gels, electrotransferred onto nitrocellulose, and immunostained with the polyclonal anti-342 SAP antibody. Immunoblots of WC protein extracts $(1.0 \mu \mathrm{g})$ of isolate AH-342 were immunostained with a $1: 25$ dilution of an acute serum specimen obtained during the bacteraemic phase of the illness.

Biological effects. To assess the potential role of the S layer of AH342 in pathogenicity, purified SAP from this strain was injected alone (intravenously) or in combination (intraperitoneally) with the homologous (A. hydrophila AH-342) or heterologous (A. hydrophila NMRI-7; A. caviae ATCC 15468) strains into female Swiss-Webster mice as previously outlined. Mortality was evaluated over a seven-day period

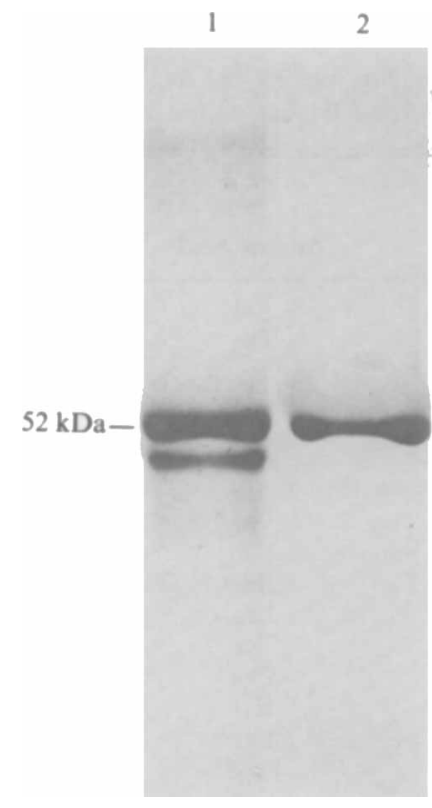

Fig. 1. SDS-PAGE $(10 \%$, w/v) of Coomassie-blue-stained WC (lane 1 , containing $30 \mu \mathrm{g}$ ) and glycine-extracted (lane 2, containing $5 \mu \mathrm{g}$ ) proteins from strain AH 342. Arrow indicates position of the SAP.

and compared to control animals (Paula et al., 1988; Kokka et al., 1991).

\section{Results}

\section{Case history and strain identification}

The Aeromonas strain was isolated from a patient with signs of bacterial sepsis at The Mount Sinai Hospital, NY. The strain was biochemically identified in our laboratory as belonging to the $A$. hydrophila phenospecies, although it possessed several unusual markers for this group, including a negative lysine decarboxylase reaction and failure to produce acid from arabinose or salicin. By both multilocus enzyme electrophoresis and DNA-DNA hybridization (Kokka et al., 1991a), this strain resided in hybridization group (HG) 1 and, therefore, belongs to $A$. hydrophila (sensu stricto). The strain was autoagglutination-positive and belonged to serogroup $0: 11$. Transmission electron microscopic studies of thin sections of the bacterium indicated that it possessed an $\mathrm{S}$ layer.

\section{Protein analysis and SAP purification of AH-342}

Two major proteins of strain AH-342 with molecular masses of approximately 52 and $50 \mathrm{kDa}$ were present in both whole-cell and outer membrane (sarkosyl-treated) fractions, respectively (Fig. 1, lane 1). The $52 \mathrm{kDa}$ SAP 
Table 2. Amino acid composition of tetragonal $S$ layer proteins

Data for TF7 and A450 were derived from Dooley et al. (1988a). Hydrophobic residues were calculated from the following amino acids: V, M, I, L, A, F, W, P.

\begin{tabular}{cccc}
\hline \hline & \multicolumn{3}{c}{ Molar percentage in: } \\
\cline { 2 - 4 } Amino Acid & A. hydrophila AH-342 & A. hydrophila TF7 & A. hydrophila A450 \\
\hline Asx & $12 \cdot 3$ & $15 \cdot 4$ & $14 \cdot 9$ \\
Thr & $7 \cdot 6$ & $7 \cdot 1$ & $8 \cdot 8$ \\
Ser & $6 \cdot 0$ & $6 \cdot 8$ & $3 \cdot 9$ \\
Glx & $6 \cdot 2$ & $8 \cdot 9$ & $9 \cdot 5$ \\
Pro & $2 \cdot 4$ & $2 \cdot 4$ & $2 \cdot 3$ \\
Gly & $9 \cdot 7$ & $8 \cdot 3$ & $4 \cdot 7$ \\
Ala & $16 \cdot 5$ & $12 \cdot 7$ & $8 \cdot 4$ \\
Val & $9 \cdot 5$ & $7 \cdot 5$ & $8 \cdot 4$ \\
Met & $1 \cdot 2$ & $1 \cdot 5$ & $1 \cdot 0$ \\
Ile & $3 \cdot 2$ & $2 \cdot 8$ & $5 \cdot 1$ \\
Leu & $9 \cdot 2$ & $8 \cdot 8$ & $10 \cdot 1$ \\
Tyr & $2 \cdot 6$ & $3 \cdot 2$ & $1 \cdot 9$ \\
Phe & $4 \cdot 0$ & $4 \cdot 4$ & $7 \cdot 3$ \\
His & $0 \cdot 4$ & $0 \cdot 6$ & $1 \cdot 1$ \\
Lys & $7 \cdot 0$ & $8 \cdot 5$ & $6 \cdot 1$ \\
Arg & $2 \cdot 2$ & $2 \cdot 1$ & $4 \cdot 3$ \\
Cys & $0 \cdot 0$ & $0 \cdot 0$ & $0 \cdot 0$ \\
Trp & ND & $0 \cdot 7$ & $1 \cdot 8$ \\
Total no. of & & & \\
residues per mol & 498 & 520 & 473 \\
Apparent molecular mass (Da) & 52000 & 52000 & 49200 \\
Hydrophobic & & & 41 \\
residues (\%) & 46 & 41 & 45 \\
\hline \hline
\end{tabular}

ND, not determined

was selectively removed from the cell surface by extraction with glycine/ $\mathrm{HCl}$ buffer (Fig. 1, lane 2). Isoelectric focusing of the SAP indicated a pI of 4.65, which is similar to values previously reported for SAPs from $A$. hydrophila TF7 (4.60) and $A$. veronii biotype sobria ATCC 9071 (4.70). A $500 \mu \mathrm{g}$ quantity of this protein was then prepared for further analysis.

\section{Amino acid analysis}

The SAP of strain AH-342 was composed of approximately 498 residues (Table 2 ) with $61.7 \%$ aliphatic, $6.6 \%$ aromatic, $1.2 \%$ sulphur-containing, $2.4 \%$ imino, $18.5 \%$ dicarboxylic, and $9.6 \%$ basic amino acids. This composition was similar to those of $A$. hydrophila TF7 and $A$. salmonicida A450, the major differences observed being the higher content of alanine and glycine residues in the mesophilic species, while the psychrophilic strain (A450) contained larger amounts of arginine and phenylalanine. No cysteine residues were identified in this analysis, in accordance with previous findings for TF7 and A450 (Dooley et al., 1988a); the content of hydrophobic residues $(41-46 \%)$ was similar for all three SAPs.

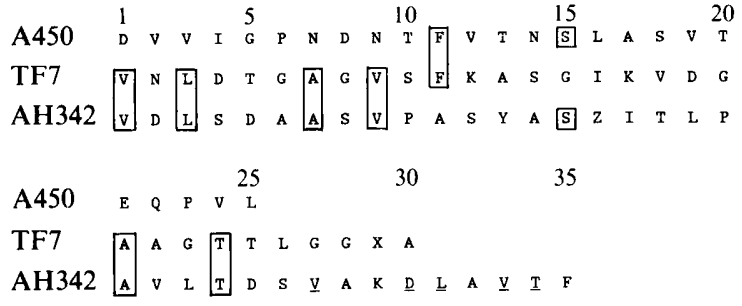

Fig. 2. N-terminal sequence of SAP from A. hydrophila AH-342. Data from Dooley et al. (1988a) are shown for comparison; boxes indicate positions of identity. Underlined amino acids have not been positively identified.

\section{Amino-terminal sequence}

The N-terminal sequence of the first 35 amino acids of AH-342 SAP was determined by Edman degradation and compared to published sequences for the SAP of TF7 and A450 (Dooley et al., 1988a). Over the first 25 amino acids, six positions showed identity between $\mathrm{AH}-$ 342 and TF7 (24\% homology, Fig. 2); in all six instances, neutral amino acids (valine, alanine, leucine, and threonine) were involved. Negligible similarity was 


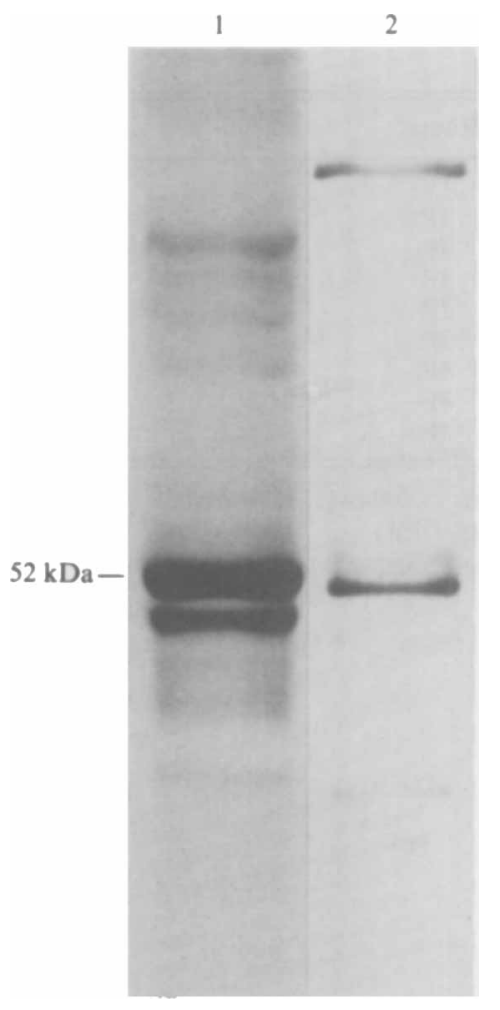

Fig. 3. SDS-PAGE $(10 \%, w / v)$ of WC proteins from strain AH 342. AH $342(30 \mu \mathrm{g})$ Coomassie blue-stained (lane 1) and AH $342(5 \mu \mathrm{g})$ immunoblotted with anti-342 SAP antibody diluted. 1:1000 (lane 2). observed between $\mathrm{AH}-342$ and A450 where only a single position (serine at position 15) was identical, with an overall homology of $4 \%$.

\section{Polyclonal antibody}

Polyclonal antisera raised against the $S$ layer of $A$. hydrophila 342 reacted with the $52 \mathrm{kDa}$ SAP of this strain when whole cell protein extracts were immunoblotted with these antibodies (Fig. 3, lane 2). Also observed by this staining procedure was a high-molecular-mass LPS band (Fig. 3, lane 2) which was not apparent upon Coomassie blue staining of whole cell protein extracts of AH-342 (Fig. 3, lane 1). This LPS reactivity was due to polysaccharide contamination of the original glycineextracted preparations of the SAP of AH-342.

To determine the specificity of these antibodies, the whole cell protein extracts from a variety of typical and atypical serogroup $0: 11$ strains of differing genotypes and phenotypes were evaluated by Western blotting. As can be seen in Fig. 4, the SAPs from three S layerpositive $A$. hydrophila strains reacted with SAP antisera (arrow, lanes 1, 2, and 4) with an intensity similar to that of the homologous isolate (lane 3). Only one $A$. hydrophila strain (LL1) had a SAP that was unreactive with these antibodies. Two O:11 A. hydrophila strains that were S-layer-negative also failed to demonstrate immunoreactive bands in the $50-55 \mathrm{kDa}$ region (lanes 6 and 7);

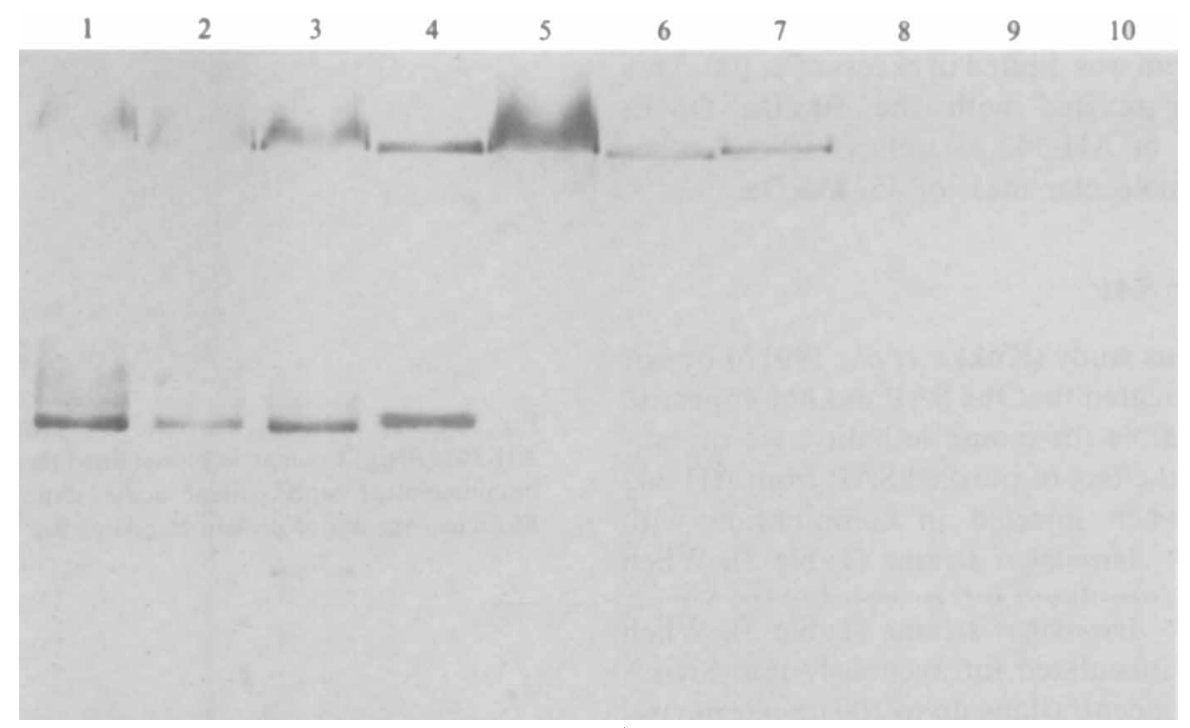

Fig. 4. SDS-PAGE $(10 \%$, w/v) of WC proteins $(1.0 \mu \mathrm{g})$ from serogroup $0: 11$, SAP positive (lanes $1-5$ and $8-10)$ and SAP negative (lanes 6 and 7) Aeromonas strains immunoblotted with anti-342 SAP antibody. NMRI-54 (lane 1), 121 (lane 2), 342 (lane 3), $1113-76$ (lane 4), LLl (lane 5), A179 (lane 6), A310 (lane 7), 180 (lane 8), 9071 (lane 9), and 28 (lane 10). 
Table 3. Biological effects of SAP, alone or in combination

\begin{tabular}{lcccccr}
\hline \hline Strain & Dose (c.f.u.) & Treatment & SAP $(\mu \mathrm{g}) \dagger$ & Route $\neq$ & Mortality & $(\%)$ \\
\hline AH-342 & - & - & 100 & IV & $0 / 5$ & $(0)$ \\
NMRI-7 & $1 \times 10^{8}$ & - & - & IP & $5 / 5$ & $(100)$ \\
NMRI-7 & $2 \times 10^{7}$ & - & - & IP & $0 / 5$ & $(0)$ \\
NMRI-7 & $2 \times 10^{6}$ & - & - & IP & $0 / 5$ & $(0)$ \\
NMRI-7 & $2 \times 10^{6}$ & - & 50 & IP & $13 / 15$ & $(87)$ \\
NMRI-7 & $2 \times 10^{6}$ & - & 5 & IP & $2 / 5$ & $(40)$ \\
NMRI-7 & $2 \times 10^{6}$ & - & $0 \cdot 5$ & IP & $0 / 5$ & $(0)$ \\
15468 & $2 \times 10^{7}$ & - & 50 & IP & $0 / 5$ & $(0)$ \\
AH-342 & $1 \times 10^{8}$ & Anti-SAP & - & IP & $20 / 20$ & $(100)$ \\
\hline \hline
\end{tabular}

* The $50 \%$ lethal doses (IP) in Swiss-Webster mice for each strain are as follows: $A$. hydrophila AH-342 $\left(1 \times 10^{7}\right)$, A. hydrophila NMRI-7 $\left(4 \times 10^{7}\right)$, and $A$. caviae ATCC $15468^{\mathrm{T}}\left(5 \times 10^{8}\right)$.

$\dagger$ Purified SAP (surface array protein) from $A$. hydrophila AH-342 as described in Methods.

$\ddagger I V$, intravenous; IP, intraperitoneal.

all of these strains exhibited high-molecular-mass LPS bands similar to that observed with AH-342 in Fig. 3. For S-layer-positive $A$. veronii biotype sobria isolates, no bands were detected whatsoever (lanes 8-10). This finding was repeatedly demonstrated by performing immunoblots of these strains (whole cell) against AH-342 anti-SAP antibodies.

\section{In vivo response to $S A P A H-342$}

Limited serum was available from the patient infected with AH-342 during the course of his bacteraemic episode. When this acute serum was immunoblotted at a 1:25 dilution against the whole cell protein extract of AH-342, immunoreactive epitopes on the $52 \mathrm{kDa}$ SAP were detected (Fig. 5, lane 2). This reactivity was lost when the acute serum was diluted in excess of $1: 100$. This acute serum also reacted with the $50 \mathrm{kDa}$ OMPassociated protein of AH-342 as well as several other minor species of molecular mass of 45-75 kDa.

\section{Biological effects of SAP}

Although a previous study (Kokka et al., 1991 b) by our laboratory had indicated that the SAP did not appear to be directly responsible for mouse lethality, we investigated the biological effect of purified SAP from AH-342 either alone or when injected in combination with heterologous SAP- Aeromonas strains (Table 3). When purified SAP was inoculated intravenously into SwissWebster mice at concentrations up to $100 \mu \mathrm{g}$ per mouse, no morbidity or mortality was observed for $7 \mathrm{~d}$ postinoculation. Because isogenic mutants (SAP-) of $A$. hydrophila and $A$. veronii biotype sobria are presently unavailable, we evaluated whether purified SAP could enhance the infectivity of selected $\mathrm{SAP}^{-}$strains upon

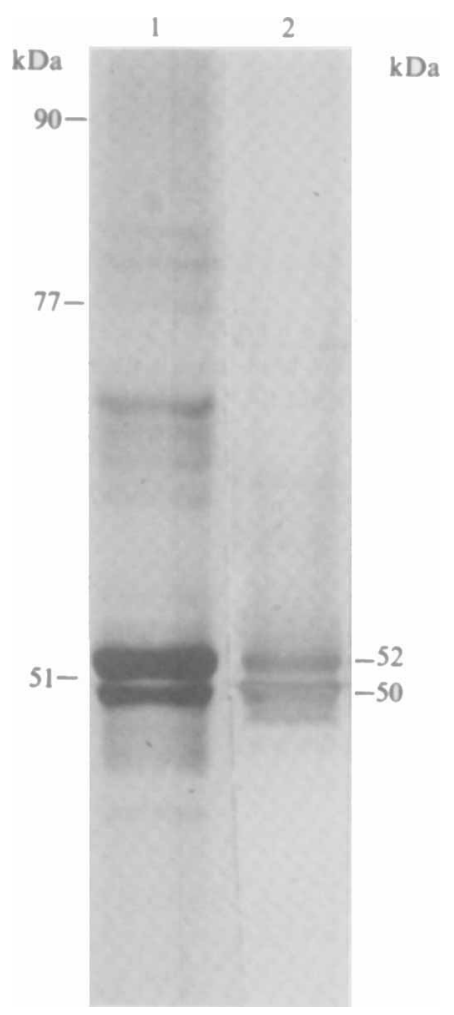

Fig. 5. SDS-PAGE $(10 \%, w / v)$ of WC proteins from strain AH 342. AH $342(30 \mu \mathrm{g})$ Coomassie blue-stained (lane 1) and AH $342(1.0 \mu \mathrm{g})$ immunoblotted with patient acute serum diluted 1:25 (lane 2). Molecular masses of protein standards are shown.

intraperitoneal injection. When $50 \mu \mathrm{g}$ SAP was mixed with $2 \times 10^{6}$ c.f.u. of $A$. hydrophila NMRI-7 and coinoculated into outbred mice, significant mortality was observed $(87 \%)$ despite the fact that the bacterial concentration was greater than one $\log _{10}$ (approx. 30- to 
70-fold) below the $\mathrm{LD}_{50}$ value for the challenge strain. This effect was directly attributable to the SAP as increasing dilutions (10- to 100 -fold) of this protein prior to co-infection with NMRI-7 resulted in further decreases in observed mortality $(60 \%-100 \%)$; control mice receiving only NMRI-7 also did not succumb to infection. To determine whether this enhancement in the relative infectivity of mesophilic aeromonads was a general phenomenon or strain-specific, we repeated the same assay using $A$. caviae ATCC $15468^{\mathrm{T}}$, an isolate that shares somatic epitopes with S-layer-positive $A$. hydrophila strains (atypical O:11). Results of this assay indicate that when ATCC 15468 was injected at a concentration approx. 30-fold below its mean $\mathrm{LD}_{50}$, along with $50 \mu \mathrm{g}$ SAP, no mortality was observed. Similar results were also found when AH-342 was pre-incubated with a $1: 10$ to $1: 100$ dilution of polyclonal anti-SAP (AH-342) prior to mouse inoculation at 10 times the mean $\mathrm{LD}_{50}$.

\section{Discussion}

Recent areas of intensified scientific interest concerning the genus Aeromonas have centred on the identification and characterization of reputed virulence factors produced by aeromonads that may be operative in disease pathogenesis in warm- and cold-blooded animals (Janda, 1991). Factors currently thought to potentially play such roles in intestinal infections include a cytolytic enterotoxin (beta-haemolysin), a cytotonic enterotoxin, and a mini-pilin; studies on such factors are hampered by the present lack of an appropriate animal model in which to reproduce faithfully the diarrhoeal syndrome (Janda, 1991).

Another molecule potentially involved in virulence is the SAP, which self-assembles at the cell surface to form an $\mathrm{S}$ layer in certain strains belonging to the genospecies $A$. salmonicida, $A$. hydrophila, and $A$. veronii. Although $\mathrm{S}$ layers are found in both saprophytic and pathogenic bacteria, an increasing number of species implicated in human disease, including Campylobacter fetus, Mycobacterium bovis, Clostridium difficile, and Wolinella recta (Sleytr \& Messner, 1988) have been shown to produce such layers. In most instances, the exact function of such layers is unknown; however, in the case of one organism ( $A$. salmonicida), possession of an $\mathrm{S}$ layer has been unequivocally linked to disease-producing capabilities in salmonids (Trust, 1986; Janda, 1991).

In mesophilic species, S-layer-positive Aeromonas strains have been previously linked to invasive disease (notably bacteraemia) and, less frequently, associated with fulminant wound infections and cases of colitis. Studies comparing the frequency of these strains recovered from humans, animals, and environmental sources indicate that these strains have a particular propensity for causing human illness and may have a selective advantage in causing significant morbidity and mortality in humans (Janda et al., 1987; Kokka \& Janda, 1990). On the biochemical level, S-layer-positive strains share additional features, including a homogeneous $O$-polysaccharide side-chain profile and the ability to autoagglutinate in liquid media (Dooley \& Trust, $1988 b$; Kokka et al., 1990).

Biochemical studies performed on the first SAP purified from a human infection indicate that although Aeromonas SAPs share a number of unifying features in common with SAPs (Sleytr \& Messner, 1983) from other pathogenic and nonpathogenic species (acidic pI, low content of sulphur-containing amino acids, similar overall amino acid content), their individual $\mathrm{N}$-terminus sequences are remarkably dissimilar $(3 \%-20 \%$ homology). Further support for this sequence divergence stems from immunoblot studies conducted on SAPs from different S-layer-containing strains where polyclonal antibodies generated against the SAP of AH-342 were found to be genospecific reacting only against HG1 strains and not HG8. Even within a genospecies, heterogeneity was observed, since one $A$. hydrophila strain, LL1, which was originally isolated from trout, failed to react in Western blot studies against the polyclonal SAP antibodies. This implies wide immunological variation in antigenic epitopes between and even among identical genospecies. Further work is presently in progress to determine the extent of this immunological variation among S-layer-bearing strains.

Previous studies from this laboratory (Kokka et al., $1991 b$ ) have suggested that the S layer is not directly responsible for mouse pathogenicity (lethality) based upon the analysis of spontaneous (leaky) mutants and atypical $\mathrm{O}: 11$ strains that are $\mathrm{SAP}^{-}$. This finding is supported by the present experiments where purified SAP from AH-342, when injected intravenously into individual mice at concentrations up to $100 \mu \mathrm{g}$, failed to produce any deleterious effect. The concentration of SAP used far exceeds the amount needed for $50 \%$ lethal doses in mice by a variety of bacterial toxins produced by many other Gram-negative and Gram-positive pathogens (Gill, 1982) suggesting that lack of virulence was not due to too small a concentration of SAP. Despite these observations, we cannot at present rule out up-regulation of SAP synthesis in vivo by leaky mutants or that the small amount of SAP secreted is sufficient for virulence in mice.

While these cumulative results do not support a major role for SAP in the final events in pathogenesis, other studies do suggest that SAP may contribute to virulence. First, we detected a specific immune response in vivo to the SAP from AH-342 during the acute phase of the 
patient's bacteraemic illness further extending our observations on the role of these strains in extraintestinal disease. The fact that the acute serum of the patient reacted most strongly against the AH-342 SAP indicates that this protein is highly immunogenic in vivo, and suggests an important role for this molecule in the infectious process. Since the completion of the present study, we have demonstrated a similar in vivo response to SAPs from other Aeromonas strains involved in invasive wound infections, again suggesting an important role in pathogenesis. Secondly, although SAP was not lethal by itself, it enhanced the virulence of $\mathrm{SAP}^{-}$strains when mixed and co-injected with $A$. hydrophila NMRI-7; this effect could be diluted and eventually nullified by adding concentrations of SAP below $0.5 \mu \mathrm{g}$. We have not to date determined the actual extent of enhancement of virulence by this molecule with a variety of strains, although from the data on $A$. caviae ATCC $15468^{\mathrm{T}}$, the effect appears to be somewhat strain-specific. How SAP enhances virulence in vivo is unknown, although one attractive possibility is that SAP is antiphagocytic against peritoneal macrophages. Previous studies conducted on the $\mathrm{S}$ layer of $A$. salmonicida have indicated that the paracrystalline surface array may confer resistance to phagocytosis and complement-mediated lysis, and this molecule may additionally function in nature as a barrier to predation by parasitic bacteria such as Bdellovibrio bacteriovorus (Koval \& Hynes, 1991; Janda, 1991). Furthermore, purified S-layer material has been shown to reassemble on the surface of S-layerminus strains of $A$. salmonicida to form a single confluent layer (Griffiths \& Lynch, 1990). This situation may be similar to the enhancement of virulence observed with $A$. hydrophila NMRI-7 in mice when preincubated with AH-342 SAP. Definitive evidence demonstrating the role of SAP in S-layer-positive strains will require isogenic mutants $\left(\mathrm{SAP}^{-}\right)$constructed using transposon mutagenesis.

The results of this investigation provide the first demonstration of a humoral response to SAP in vivo during the course of systemic infection and provide the first evidence toward a possible role for SAP during the course of disseminated illnesses in humans. With respect to this later observation, the results with $A$. caviae ATCC $15468^{\mathrm{T}}$ and $50 \mu \mathrm{g}$ of SAP indicate that 15468 lacks the gene(s) necessary to kill mice under conditions similar to those used for NMRI-7. Since virulence is polygenic in nature (Falkow, 1990) for most micro-organisms, this result is not unexpected. Current studies are in progress to determine how other Aeromonas genes and their products of SAP+ ${ }^{+}$and $\mathrm{SAP}^{-}$strains interact to cause the observed morbidity and mortality in mice.
We wish to thank Gary Schoolnik for helpful discussions and assistance in the amino acid analysis of our SAP, Lyndon Oshiro for electron microscopic studies, Warren Hill and the staff of the Biologics Unit of the Microbial Diseases Laboratory for help in the generation of polyclonal SAP antibodies, and Lu-Anne Dodge for typing this manuscript.

\section{References}

Dooley, J. S. G., McCubbin, W. D., Kay, C. M. \& Trust, T. J. $(1988 a)$. Isolation and biochemical characterization of the $S$ layer protein from a pathogenic Aeromonas hydrophila strain. Journal of Bacteriology 170, 2631-2638.

DoOLEY, J. S. G. \& TRUST, T. J. (1988b). Surface protein composition of Aeromonas hydrophila strains virulent for fish: identification of a surface array protein. Journal of Bacteriology 170, 499-506.

FALKow, S. (1990). The 'Zen' of bacterial pathogenicity. In Molecular Basis of Bacterial Pathogenesis. Edited by B. H. Iglewski and V. L. Clark. Academic Press: San Diego.

GiLl, D. M. (1982). Bacterial toxins: a table of lethal amounts. Microbiological Reviews 46, 86-94.

GRIFFITHS, S. G. \& LYNCH, W. H. (1990). Characterization of Aeromonas salmonicida variants with altered cell surfaces and their use in studying surface protein assembly. Archives of Microbiology 154, 308-312.

Ho, A. S. Y., Mietnzer, T. A., Smith, A. J. \& Schoolnik, G. K. (1990). The pili of Aeromonas hydrophila: identification of an environmentally regulated 'mini pilin.' Journal of Experimental Medicine 172, 795-806.

JANDA, J. M. (1991). Recent advances on the taxonomy, pathogenicity, and infectious syndromes associated with the genus Aeromonas. Clinical Microbiology Reviews 4, 397-410.

Janda, J. M., Oshiro, L. S., Abbott, S. L. \& Duffey, P. S. (1987). Virulence markers of mesophilic aeromonads: association of the autoagglutination phenomenon with mouse pathogenicity and the presence of a peripheral cell-associated layer. Infection and Immunity 55, 3070-3077.

KOKKA, R. P. \& JANDA, J. M. (1990). Isolation and identification of autoagglutinating serogroup $0: 11$ Aeromonas strains in the clinical laboratory. Journal of Clinical Microbiology 28 1297-1299.

KoKKA, R. P., Vedros, N. A. \& JANDA, J. M. (1990). Electrophoretic analysis of the surface components of autoagglutinating surface array protein-positive and surface array protein-negative Aeromonas hydrophila and Aeromonas sobria. Journal of Clinical Microbiology 28 , 2240-2247.

Kokka, R. P., Janda, J. M., Oshiro, L. S., Altwegg, M., Shimada, T., Sakazaki, R. \& Brenner, D. J. (1991a). Biochemical and genetic characterization of autoagglutinating phenotypes of Aeromonas species associated with invasive and noninvasive disease. Journal of Infectious Diseases 163, 890-894.

KoKKA, R. P., VEDRos N. A. \& JANDA, J. M. (1991 b). Characterization of classic and atypical serogroup O:11 Aeromonas: evidence that the surface array protein is not directly involved in mouse pathogenicity. Microbial Pathogenesis 10, 71-79.

Koval, S. F. \& HYNES, S. H. (1991). Effect of paracrystalline protein surface layers on predation by Bdellovibrio bacteriovorus. Journal of Bacteriology 173, 2244-2249.

Paula, S. J., Duffey, P. S., Abbott, S. L., Kokka, R. P., Oshiro, L. S., Janda, J. M., Shimada, T. \& SaKazaKi, R. (1988). Surface properties of autoagglutinating mesophilic aeromonads. Infection and Immunity 56, 2658-2665.

SLeYTR, U. B. \& Messner, P. (1983). Crystalline surface layers on bacteria. Annual Reviews of Microbiology 37, 311-339.

SleYtR, U. B. \& Messner, P. (1988). Crystalline surface layers on procaryotes. Journal of Bacteriology 170, 2891-2897.

Trust, T. J. (1986). Pathogenesis of infectious diseases of fish. Annual Review of Microbiology 40, 479-502. 